\title{
Ocupar, urbanizar, regularizar desde la acción colectiva: indagaciones sobre el barrio Malvinas II de La Plata
}

\author{
Occupy, urbanize, regularize from collective action: \\ inquiries about the Malvinas II neighborhood of La Plata
}

\author{
Andrea Di Croce Garay ${ }^{1}$ \\ Fecha de recepción: 28-11-2020 - Fecha de aceptación: 23-06-2021 \\ Hábitat y Sociedad (ISSN 2173-125X), n. ${ }^{\circ}$ 14, noviembre de 2021, pp. 33-50. \\ https://doi.org/10.12795/HabitatySociedad.2021.i14.03
}

\begin{abstract}
The experiences of social production of habitat in Latin America are countless. In all its corners, families organize themselves and, with the strength and time remaining from working hours, build their homes and neighborhoods. In these practices, organized neighborhood groups tend to develop links with social organizations, professional groups and / or state agencies that accompany the experiences in different ways. This paper aims to review what happened in the Malvinas II neighborhood of La Plata (Buenos Aires, Argentina), where collective action was the protagonist of the process of occupation, urbanization and ownership regularization of the neighborhood. To develop the work, secondary sources were analyzed that allowed us to know the current housing situation of the neighborhood; the existing bibliography on the case was reviewed; and interviews were conducted with residents of the neighborhood, state workers and members of social organizations participating in these processes. As a result, it was possible to reconstruct the housing process of the neighborhood, distinguish the contributions and difficulties of interactoral participation, and recognize the relevance that collective action (crossed by the temporalities and porosities of the group of actors) has in improving the popular habitat.
\end{abstract}

\section{Key words}

Collective Creation; Popular Settlements; Social Production of Habitat; La Plata

\section{Resumen}

Las experiencias de producción social del hábitat en Latinoamérica son incontables. En todos sus rincones, las familias se organizan y, con la fuerza y tiempo que resta de las jornadas laborales, construyen sus viviendas y sus barrios. En estas prácticas, los grupos de vecinos y vecinas organizados suelen desarrollar vínculos con organizaciones sociales, colectivos de profesionales y/o agencias estatales que acompañan de distintas formas las experiencias. Este trabajo se propone revisar lo sucedido en el barrio Malvinas II de La Plata (Buenos Aires, Argentina), donde la acción colectiva fue protagonista del proceso de ocupación, urbanización y regularización dominial del barrio. Para desarrollar el trabajo se analizaron fuentes secundarias que permitieron conocer la situación habitacional actual del barrio; se revisó la bibliografía existente sobre el caso; y se realizaron entrevistas a habitantes del barrio, personal trabajador estatal e integrantes de organizaciones sociales partícipes en esos procesos. Como resultados, se logró reconstruir el proceso habitacional del barrio, distinguir los aportes y dificultades de la participación interactoral, y reconocer la relevancia que la acción colectiva (atravesada por las temporalidades y porosidades propias del conjunto de actores) tiene en el mejoramiento del hábitat popular.

\section{Pallabras clave}

Acción colectiva; Producción social del hábitat; Asentamientos populares; La Plata Mgtr. en Estudios Urbanos (UNGS), Arquitecta (UNLP); becaria doctoral de CONICET; Centro Interdisciplinario de Estudios
Complejos (CIEC-FAU-UNLP). E-mail: andreadicroce@ @otmail.com. ORCID: https://orcid.org/0000-0002-7173-6555. 


\section{Introducción}

Podríamos decir que las ciudades latinoamericanas son una especie de muñeca rusa: dentro de ella encontramos otras ciudades, cada una parecida pero distinta a las demás. Varias de esas muñecas son habitadas por los sectores populares de estas latitudes, ese "conglomerado que reúne mundos heterogéneos, entre los que se cuentan indígenas, campesinos, trabajadores informales y clase obrera urbana" (Svampa, 2009, p.1). ${ }^{2}$ Tras décadas de procesos migratorios rural-urbano motorizados por la mecanización del campo y por la expulsión de comunidades de sus territorios, los grandes centros urbanos se convirtieron en sedes de esperanza donde muchas personas buscan resolver el acceso al trabajo, al alimento, a la vivienda. Sin embargo, las dificultades no tardan en hacerse presentes: las ofertas habitacionales de estas ciudades no están al alcance de toda la población, ya sea por estar concentradas en pocas manos, como por presentar restricciones para acceder a ellas (tales como antecedentes laborales, garantías, valores que las ubican por fuera de las posibilidades de grandes sectores, etc.). La producción social del hábitat (PSH) aparece, entonces, como opción. Con este concepto la Coalición Internacional del Hábitat propone nombrar, desde la década de 1990, a la "masiva capacidad de autoproducción de los sectores populares respecto de las viviendas, pedazos de la ciudad y, en general, los territorios que habitan. Un fenómeno que se ha reiterado a lo largo y ancho del continente" (Di Virgilio y Rodriguez, 2014, p.14). Muchas de esas experiencias podrían inscribirse en el concepto de "acción colectiva”, acuñado por Tilly (1978). El autor define a la acción colectiva como aquella desarrollada por un grupo de personas con intereses comunes, organizado con estructuras más o menos formales, que desarrolla prácticas de acción concretas para alcanzarlos. Según este autor, la acción colectiva se compone de cuatro elementos: intereses en común, organización del colectivo, movilización (o paso de la reflexión y auto-organización a la acción) y contexto político-social-cultural-económico (que, en mayor o menor medida, influirá en el desenlace de la acción colectiva). Estos cuatro elementos aparecen de forma recurrente en las prácticas de $\mathrm{PSH}$, donde a través de entramados interactorales compuestos por las personas pobladoras y distintos tipos de organizaciones, el hábitat popular surge, crece, se mejora, al calor del momento político en el que se desarrolla. A través de la autoconstrucción, la ayuda mutua, la ocupación de tierras, el mercado informal, entre otras prácticas, aquellas personas a quienes se les niega habitar la ciudad construyen sus alternativas habitacionales, desarrollando sus "agendas ocultas" (Zibechi, 2008) a través de las que buscan darse lugar allí donde las dificultades son la primera opción.

La ciudad de La Plata (Buenos Aires, Argentina) no escapa a estas realidades. Capital de provincia, una de las pocas ciudades planificadas del país, convive desde su origen con barrios donde se fueron ubicando los sectores populares (Bonafina, 2014; Del Río y González, 2018; Vallejo, 2015). La Plata es hoy una de las ciudades con mayor cantidad de barrios populares, ${ }^{3}$ y se ubica entre las ciudades de la provincia con mayor cantidad de familias viviendo en estos contextos (Registro Público Provincial de Villas y asentamientos Precarios, RPPVAP, 2015). Así como en el resto del continente, en estos enclaves se dan procesos de autoconstrucción del hábitat donde se busca llevar la ciudad a los barrios, caracterizados por la acción colectiva de sus habitantes, acompañados en algunas ocasiones por organizaciones sociales. 
Con el objetivo de reconocer estas prácticas, indagar en sus características y posibles aportes a otros procesos barriales así como a políticas estatales, en este trabajo ${ }^{4}$ nos proponemos conocer lo sucedido en el proceso habitacional del asentamiento Malvinas II de esta ciudad: cómo se accedió a las tierras, cómo fue su proceso de urbanización, qué características tuvo el proceso a través del cual se buscó su regularización dominial. En esas indagaciones se observan las acciones colectivas de les habitantes del barrio, acompañadas y/o impulsadas desde organizaciones sociales, estudiantes universitarios y profesionales, y actores estatales, buscando reconocer los aportes, el lugar y las dificultades que supusieron. Para ello se apela a la tipología de actores retomada de Herzer y Pírez $(1993 ; 1995)$ : actores estatales (oferentes de programas habitacionales, subsidios y asistencia técnica y social), actores económicos, actores comunitarios (protagonizados por las propias personas afectadas de las demandas habitacionales, en conjunto o no con organizaciones sociales; aportando a veces solidaria y colectivamente su trabajo para la construcción de viviendas y la urbanización de barrios). A partir de ello, se trabajó tanto con técnicas de los métodos cualitativos, como con algunas de los cuantitativos. En primer lugar, se indagó en el estado de la situación habitacional barrial, para lo cual se utilizaron diversas fuentes secundarias de acceso público: Registro público Provincial de Villas y Asentamientos Precarios (RPPVAP), Registro Nacional de Barrios populares (ReNaBaP). También se indagó en las páginas web y redes sociales de las organizaciones sociales intervinientes. A su vez, se realizaron entrevistas exploratorias a las personas trabajadoras y ex trabajadoras de la ex Subsecretaría Social de Tierra Urbanismo y Vivienda (SSTUV), una entrevista semi-estructurada a una referente ${ }^{5}$ del Movimiento Evita (ex funcionaria pública), y otras a dos referentes barriales. Para acceder a estos referentes se utilizaron estrategias como contactos previos, pedidos formales a las organizaciones participantes, llamados telefónicos, etc. Asimismo, se utilizó la técnica conocida como "bola de nieve" que consiste en utilizar las redes personales de los contactos iniciales para acceder progresivamente a otros informantes (Piovani, 2007). También se realizó una exhaustiva revisión bibliográfica en los repositorios bibliográficos públicos de la UNLP. Con la revisión de la información recabada es que se llevó adelante la reconstrucción de la historia del barrio, así como las reflexiones y conclusiones aquí presentadas.

\section{Malvinas II: habitar desde la acción colectiva. Aportes y dificultades}

Propio de las latitudes latinoamericanas, el desarrollo del barrio Malvinas II se desarrolló de forma "inversa" (Pírez, 2016): primero fue habitado, luego mejorado, y más tarde (o en paralelo) comenzó a buscar vías para ser regularizado. En estos procesos encontramos el despliegue de una red multiactoral que permitió avanzar incorporando aspectos colectivos, que a continuación observaremos.

\section{Origen de Malvinas II: ocupación de tierras ante desdoblamientos familiares y escasez de posibilidades habitacionales}

La delegación municipal Melchor Romero de La Plata es sede de un conjunto de 22 barrios populares que en los últimos 30 años con-
4 El trabajo es parte de la tesis "Reconocer las resistencias. La dimensión colectiva en procesos de regularización dominial de asentamientos informales en La Plata”, de la Maestría en Estudios Urbanos de la UNGS. EN este trabajo se recogen parte de los aportes que se dieron durante su defensa. Asimismo, el artículo se enmarca en el Proyecto I+D+i "Producción Social del Hábitat en áreas metropolitanas del Norte y el Sur Global: políticas, instituciones y movilización social" Ref.: (PID2019-105205RB-100), financiado por el Ministerio de Ciencia, Innovación y Universidades (España).

5 Con "referente" nos referiremos a las personas coordinadoras de las organizaciones comunitarias con inscripción territorial, que logran construir referencia en los barrios (Zibecchi, 2019). En este artículo consideraremos que las personas referentes pueden o no ser pobladoras de los barrios populares. Lo que las convierte en referentes es el reconocimiento por parte de otras personas como integrante con determinada jerarquía dentro de la organización a la que pertenece. 
virtieron a esta delegación en una de las más pobladas por asentamientos populares (Figura 1). Hasta la década de 1990 predominaban allí usos agrícolas o extractivos, que fueron reemplazados en las últimas décadas por usos residenciales, mayoritariamente ocupaciones de terrenos llevadas adelante por familias y personas pertenecientes a los sectores más empobrecidos. Desde la década del 2000 a la actualidad, se construyeron más del $60 \%$ de sus asentamientos populares (RPPVAP, 2015).

Los asentamientos Malvinas, Malvinas II e Hijos de Malvinas son parte de ese conjunto. Estos tres asentamientos linderos entre sí, se ubican en varias de las manzanas comprendidas entre las calles 33 a 40, 149 a 155 de La Plata. Paradójicamente, el resto de las manzanas del cuadrante están ocupadas por casa-quintas, canchas de fútbol y quintas de veraneo de gremios.

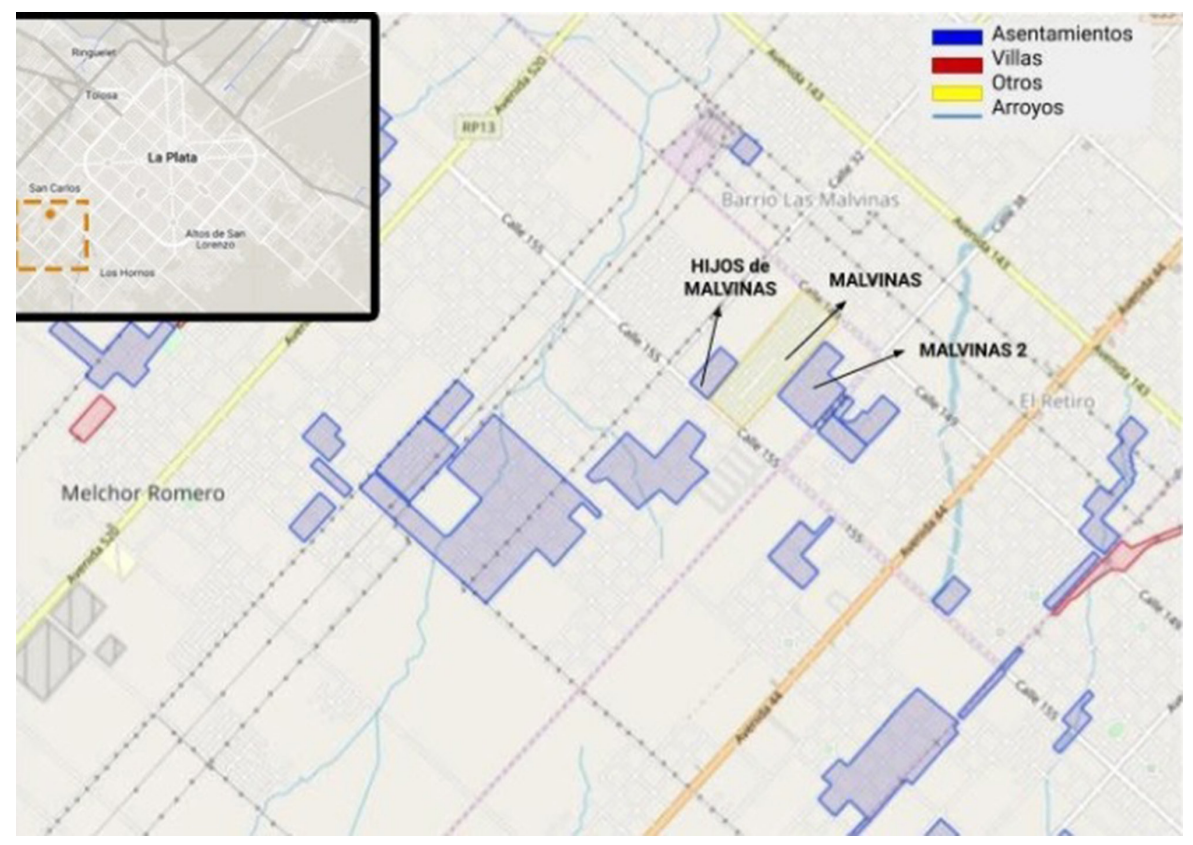

En la lectura de fotografías aéreas podemos leer el surgimiento de estos tres barrios, cuyos orígenes están vinculados (Figura 2). El barrio Malvinas (antecesor de los otros dos) es una de las intervenciones realizadas bajo la operatoria del programa Pro Tierra, desarrollada a principios de la década de 1990 mediante una intervención del Estado nacional. Inicialmente era el destino habitacional de personas vinculadas a diversas instituciones: Sindicato de Empleados de taxis, Asociación de Empleados del Ministerio de Obras Públicas de la Provincia de Buenos Aires, Comunidad Toba y Consejo de la mujer (Tamagno, 2001). Sin embargo, por estar alejados del casco urbano, las personas integrantes de las dos primeras instituciones renunciaron

Figura 1. Emplazamiento del barrio Malvinas II. FUENTE: Elaboración propia en base al RPPVAP (2015). a los 309 lotes que les habían sido asignados, que fueron ocupados por otras familias con menores posibilidades de elección del sitio donde vivir (Relli, 2008). El sector más organizado y reconocido del barrio es el habitado por familias pertenecientes a la comunidad toba, quienes construyeron sus viviendas con recursos de programas estatales, y la fuerza de trabajo de sus integrantes auto-organizados.

A fines de 2002, casi diez años después de la creación de ese barrio, el hacinamiento producto de desdoblamientos familiares llevó a varias familias de Malvinas (principalmente de las familias de la comunidad toba, aunque también hubo integrantes de otras comunidades) a ocupar las manzanas comprendidas entre las calles 36, 38, 151 y 153. Posteriormente se ocupó también la hectárea comprendida entre 36, 37, 150, 151, terminando de conformar el barrio Malvinas II. En su nombre se expresa su vínculo con el barrio Malvinas:

¿Y por qué Malvinas II? Porque en un principio nosotros íbamos donde fuera a reclamar las cosas y nos decían ¿de dónde sos? De Malvinas, decíamos. ¡Pero Malvinas tiene luz, y tiene agua! Tuvimos que hablar con el delegado, que nos mostrara el plano de Melchor Romero, [...] y decía que Melchor Romero el límite es (la calle) 38 [...]. Entonces se denomina Mal- 
vinas II porque pertenecemos a Melchor Romero. Somos como el hijito (M., Vecina entrevistada; 2019, Di Croce Garay y Jaimarena). ${ }^{6}$

Durante el año 2009, ante crecimientos familiares similares a los ocurridos en 2002, un nuevo proceso de ocupación de tierras dio origen a Hijos de Malvinas, ubicado entre las calles 33, 34, 153 y 155. De esta forma, la intervención estatal desarrollada desde el programa Pro Tierra que tuvo por objetivo crear el barrio Malvinas, terminó siendo semilla de dos barrios populares que alojaron a sus crecimientos y desdoblamientos familiares. En los próximos apartados nos dedicaremos a reconstruir particularmente el proceso de urbanización y regularización dominial de Malvinas II.

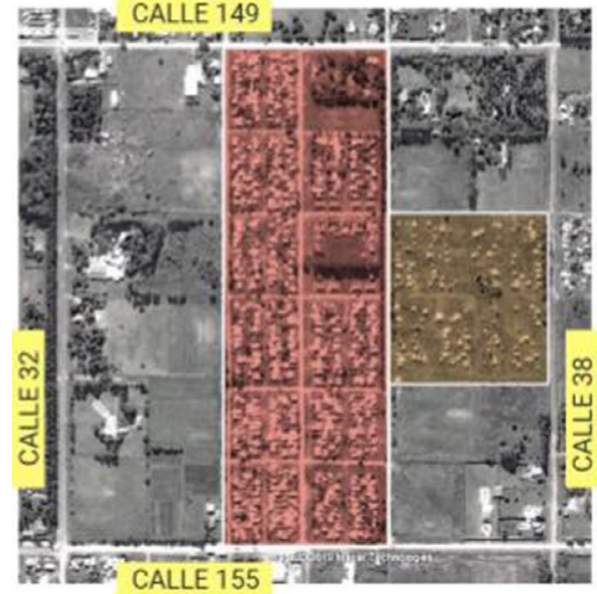

2004

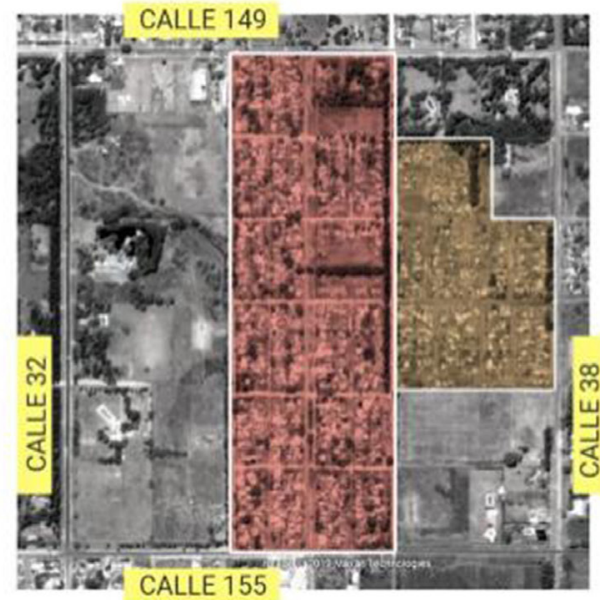

2008

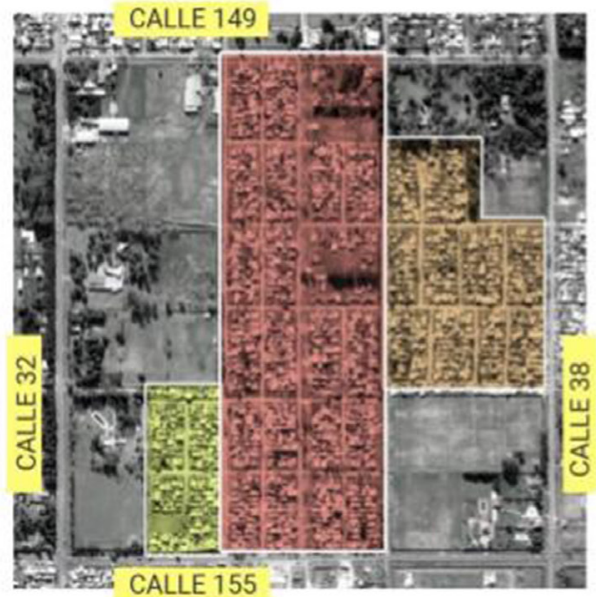

2018
Malvinas

Malvinas II
Hijos de Malvinas

\section{Del baldío al barrio: sumar uno más uno ${ }^{7}$}

Durante el año 2002, en pocos meses las 8 hectáreas que hasta entonces se encontraban vacantes se transformaron en el barrio Malvinas II al ser ocupadas por un total de 273 familias. Entre ellas se encontraban mayoritariamente integrantes de la comunidad Q'OM (migrantes de la provincia de Chaco) familiares de habitantes del barrio Malvinas, y en menor medida personas de Paraguay y criollas (término usado en el barrio para las personas inmigrantes de otras provincias). Como veremos más adelante, el origen de estas personas tendrá su reflejo en algunas de las prácticas colectivas a partir de las que se construyó el barrio. Entre estas familias encontramos coincidencias en la larga búsqueda de un lugar donde vivir previo a llegar a Malvinas II, así como en la escasez de oferta habitacional que atravesaron:

En la toma hay algunos que lo agarran para negocio, pero otros por necesidad, siempre suele pasar [...]. Las personas que están ahí es porque no tuvieron otra posibilidad. Si vos tenés plata para comprarte un lote no vas a ir al arroyo "no sé dónde" a meterte. No. Vas a ir a comprarte un buen lote donde tus posibilidades están para bancarlo, ¿no? (M., vecina de Malvinas II; 2019, Di Croce Garay y Jaimarena).

$\mathrm{Al}$ momento del amanzanamiento y del loteo, fueron los y las propias ocupantes y las primeras organizaciones sociales quienes comen-
Figura 2. Evolución de la ocupación de los barrios Malvinas, Malvinas II e Hijos de Malvinas. FUENTE: Elaboración propia sobre la base de Google Earth.
6 Una de las entrevistas fue realizada en conjunto con la tesista de grado de la carrera de Geografía (FaHCE, UNLP), Rocío Jaimarena.

7 En referencia al poema "La consigna es sencilla" de Fermín Estrella, publicado en el libro Los versos del exilio 1976-1990). Disponible en: http://www.ferminestrella. com.ar/secciones/versos/exilio/50-51. htm 


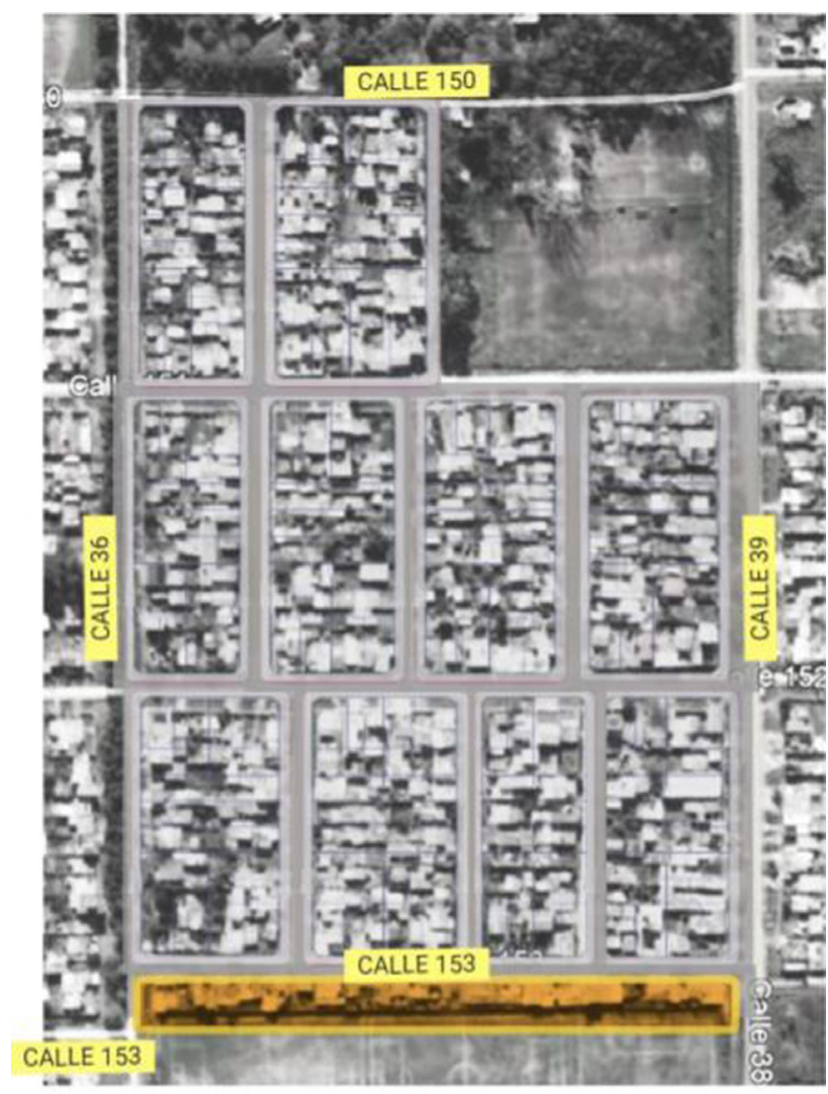

Ocupación del "paredón" en Malvinas II

Figura 3. Amanzanamiento y ocupación en barrio Malvinas II. FUENTE: Elaboración propia sobre la base de Google Earth. zaron a trabajar en la ocupación organizada de la tierra. El primer resultado fue un barrio medianamente regular, que procuró continuar la trama de los barrios aledaños. Sin embargo, más allá de los esfuerzos, las calles fueron trazadas de forma desfasada, y no se dejaron espacios verdes públicos. La posterior ocupación de una franja de tierras previstas para el trazado de la calle 153 conocida en el barrio como el "paredón" (que desarrollaremos más adelante), fue la única parte no planificada del barrio, y la excusa estatal para frenar el avance de la entrega de escrituras (Figura 3).

La distribución de lotes, su delimitación y el mejoramiento de la infraestructura en general demandaron cierto nivel de organización desde el comienzo de la ocupación (Vila, 2011). Una de las integrantes de la comunidad toba fue la encargada de la distribución de terrenos entre las primeras 50 familias que fueron llegando del barrio Malvinas primero, y de otros barrios más adelante (Villar, 2007). Miller (citado en Tamagno, 2001) "describe dos valores fundamentales que dominaban las creencias y actividades de los tobas: el mantenimiento de la armonía entre el hombre y el orden natural [...], y el interés por el bienestar de los parientes". El segundo de estos valores es fácilmente reconocible en la ocupación y urbanización de Malvinas II, proceso caracterizado por la ayuda mutua entre familias. Villar (ob. cit.) indica que "a cambio del terreno, a estas familias se les pidió que se instalasen solo si realmente necesitaban el baldío y si no tenían vivienda; que cada familia ocupase un solo lote previamente delimitado; y que la distribución de los terrenos se hiciese en forma organizada, realizando los trazados de las calles en continuidad con el trazado urbano del barrio y dejando espacios libres para el equipamiento comunitario" (Villar, 2007, p. 47). Así como señala Vila (2011, p. 77), si bien la ocupación se estableció a medida que cada familia llegaba al barrio y no fue una acción planificada (del estilo de las ocupaciones en el conurbano bonaerense durante los años ochenta), el trabajo referido al "trazado de las calles, la delimitación de los espacios libres, la asignación de lotes por familia aún sin viviendas y la demacración de cada uno de los terrenos tomados, implicó un primer acercamiento y coordinación de trabajo colectivo por parte de los vecinos recientemente instalados en el asentamiento junto con la colaboración de algunos integrantes de comunidad toba antiguamente radicada en el barrio".

Además de lo organizado por las y los propios ocupantes, la extensa participación de espacios políticos-comunitarios de los barrios Malvinas y Malvinas II que se vincularon al proceso con posterioridad (González y Silber, 2003, pp. 28-29) fue también un elemento importante en el proceso de ocupación y urbanización:

Entre 2003 y 2007 participaban todos: Quebracho, kirchneristas, Polo Obrero, CTD, todo el mundo (E., integrante del FPDS entrevistado; 2019, Di Croce Garay).

En las entrevistas realizadas y los trabajos académicos revisados encontramos a las intervenciones de las organizaciones sociales Movimiento Evita y Movimiento de Trabajadores Desocupados (MTD) 
Aníbal Verón como las de mayor extensión en el tiempo, así como de mayor trayectoria en el barrio. S bien, así como fue mencionado, la comunidad toba y sus espacios organizativos tuvieron en el inicio del barrio una fuerte presencia, en los procesos posteriores la mayor presencia fue de organizaciones sociales (en donde parte de sus integrantes viven en el propio barrio), mientras que las intervenciones de los espacios organizativos tobas tuvieron un carácter puntual ante determinados pedidos.

En el caso del Movimiento Evita, registramos relatos que indican distintas instancias de organización barrial durante los primeros años del asentamiento:

Empezamos a juntarnos primero lo que es familia, ¿no? Vimos la necesidad de cada una de nosotros, cómo podemos hacer para arrancar y para poder sustentarnos. En el medio no teníamos trabajo, y cosas así. Entonces empezamos a hacer una olla comunitaria, como se le dice, una olla popular, entre nosotros, que a eso se le fue sumando un vecino, otro vecino, y así. Y después optamos hacer un ropero comunitario [...] que también a su vez se fueron acoplando algunos vecinos. No te digo todos, dos o tres ponele y así sucesivamente (M., vecina entrevistada; 2019, Di Croce Garay y Jaimarena).

Por otro lado, a partir del contacto realizado por un vecino del barrio Malvinas, el MTD Aníbal Verón comenzó a trabajar en el barrio junto a otro grupo de habitantes. Las primeras coordinaciones tuvieron por objetivo la apertura de calles y parcelamiento en búsqueda de evitar conformar una villa. A partir de una propuesta del MTD, comenzaron a funcionar asambleas barriales con una periodicidad semanal. Las primeras asambleas se realizaban en casas de los barrios linderos, y participaban siete personas. Cuando se tuvo la necesidad de tener el espacio propio, en coordinación con el MTD se trabajó en la construcción del comedor "El Galponcito", donde funcionaron el comedor y la huerta comunitaria, en un contexto de crisis económica que acentuó las necesidades. La asamblea llegó a contar con 150 participantes. En la inserción del MTD en el barrio fue relevante el hecho de que las personas jóvenes pertenecientes a la comunidad toba no reconocían la figura de liderazgo del cacique del barrio Malvinas, y se identificaron rápidamente con la organización. ${ }^{8}$

Durante los años que siguieron a la conformación del barrio, ya habiéndose constituido el MTD Aníbal Verón Barrio Malvinas (MTS A.V B-M) - conformado en gran medida por vecinas y vecinos de Malvinas II-, se dio lugar al desarrollo paulatino de diversas actividades cooperativas y colectivas, que se complementaron con las que las propias personas ocupantes ya habían comenzado a trabajar: panadería, ropero, productivo de pollos. La conformación del Frente Popular Darío Santillán (FPDS) a fines del año 2004, ${ }^{9}$ incorporó al objetivo de satisfacer necesidades del asentamiento Malvinas II, el objetivo de "crear nuevos modelos de relaciones sociales centrados, por ejemplo, en el trabajo sin patrón y la formación desde la educación popular" (Vila, 2011, p. 90 ), así como la autogestión como forma de resignificar el origen y manejo de recursos.

Estas actividades, la pertenencia a determinadas comunidades, la vinculación previa entre algunas de estas familias, y el trabajo territorial de las organizaciones sociales, fortalecieron los vínculos entre familias del barrio, y dieron lugar a instancias de organización barrial. En
8 Tamagno (2001, cfr. p. 172) menciona que las tensiones con el líder comunal comenzaron en 1993. Algunas familias de la comunidad Q'OM pertenecientes al segundo grupo de con lotes asignados, realizaron una serie de críticas al líder de la comunidad, que se hicieron públicas y retrasaron las obras. Si bien el líder no se considera cacique (ob. cit., p. 186), su rol de presidente de la asociación civil, sus antepasados y su actual rol de pastor de la iglesia evangélica que él fundó, lo ubican en un lugar de referencia en la comunidad, que principalmente las generaciones más jóvenes no comparten.

9 Que integró junto a otras organizaciones el MTD Aníbal Verón. 
el año 2005 comenzaron a desarrollarse reuniones y asambleas, que se convirtieron luego en la Mesa barrial de Malvinas II. En este espacio confluyeron organizaciones y vecinas y vecinos de distintas procedencias para organizar respuestas colectivas a los problemas del barrio. De los temas trabajados en la Mesa, la prioridad estuvo puesta en los problemas urbanísticos: por un lado, algunas de las empresas prestatarias se negaban a conectar el servicio por la ilegalidad en la tenencia; por otro lado, existía en varias familias el temor a invertir dinero en las conexiones, y perder lo invertido en caso de ser desalojadas:

Estábamos a la vez con el tema de las tierras que era lo principal, la base de todo. De nada nos servía si nos iban a correr en algún momento, ¿no? (M., vecina de Malvinas II: 2019, DI Croce Garay y Jaimarena).

Se decidió entonces que uno de los primeros temas a abordar era la regularización del dominio del barrio.

\section{Regularización dominial: la Ley de Expropiación}

En el año 2006 se aprobó la Ley de Expropiación n. ${ }^{\circ}$ 13591, donde se promovía la expropiación de las tierras del barrio Malvinas II, para la posterior cesión a sus habitantes. Ante la indagación sobre las llaves que dieron acceso a esa Ley, las respuestas son múltiples, pero no por ello inconexas. Vínculos directos con el funcionariado público, nivel de organización del barrio mediante la Mesa Barrial, aportes de organizaciones sociales y profesionales, voluntad política, conforman una respuesta multicausal a la pregunta.

En primer lugar, para llegar al proyecto de Ley de expropiación, existieron coordinaciones en algún sentido exógenas al barrio, que vincularon a vecinos y vecinas del barrio con actores universitarios, integrantes de organizaciones sociales y personal estatal.

Por un lado, encontramos vinculaciones con integrantes de la Universidad Nacional de La Plata (UNLP): organizaciones estudiantiles, proyectos de extensión y cátedras. Estos vínculos generaron aportes en la construcción de vínculos en el grupo de la Mesa barrial de Malvinas II, así como insumos para la presentación de la Ley:

- Las vinculaciones desarrolladas desde el FPDS permitieron trabajar en talleres de huerta con estudiantes de la Facultad de Ciencias Agrarias y Forestales de la UNLP, a partir de los cuales se afianzaron vínculos entre algunas familias.

- A través de un proyecto de extensión universitaria de la Facultad de Ciencias Exactas de la misma universidad, se realizó un análisis de la potabilidad del agua que demostraron el mal estado del agua de consumo. Este análisis dio fuerza tanto al pedido de Ley como al de conexión a la red de agua. ${ }^{10}$

- Podríamos decir que hubo un aporte indirecto desde la Facultad de Arquitectura y Urbanismo. Varias de las y los integrantes de lo que fue luego el Movimiento Evita, llegaron al barrio a partir de un ejercicio proyectual para la Cátedra de Arquitectura dirigida por Daniel Togneri. A mediados de los años noventa, para el quinto año de la materia se propuso proyectar una escuela en el barrio Malvinas. La perspectiva teórica de la cátedra impulsó a las y los estudiantes a conocer el barrio e involucrarse con su 
últimos 20 años de un grupo de estudiantes, hoy profesionales. ${ }^{11}$ Unos años más tarde, una integrante de este grupo fue Subsecretaria Municipal de Inclusión Social, y se convirtió en un actor clave en los contactos desarrollados con los Estados para la aprobación de la Ley. ${ }^{12}$

Por otro lado, durante el año 2004 se realizó un censo de la población barrial, coordinado entre la Mesa barrial y residentes de la sala de salud de la calle 149 e/ 35 y 36 . Asimismo, en ese año se llevaron adelante controles periódicos de la salud de la infancia. Sumado a los análisis de potabilidad del agua realizados con anterioridad, el censo y los controles fueron insumo en la presentación de la Ley, en tanto que dieron cuenta no solo de las características de la población del barrio, sino también de la cantidad de menores de edad que lo estaban habitando, y las enfermedades vinculadas a la falta de conexión a las redes de servicios que muchos niños y niñas atravesaban.

Estos aportes se dieron en el marco de una coyuntura gubernamental en la que, por lo menos en principio y en apariencia, la regularización del hábitat popular estaba en su agenda. Una vez asumida la presidencia por Néstor Kirchner, la Subsecretaría Municipal de Inclusión Social tuvo como una de sus tareas coordinar las cooperativas municipales de trabajo, vinculadas a los programas financiados desde el Estado provincial y el nacional. Del conjunto de esos programas, en el barrio Malvinas II se propuso dar lugar a los relacionados al mejoramiento habitacional:

Nuestra tarea era lograr salir de la clandestinidad de la vivienda tan precaria y tener la oportunidad de generar una vivienda de material construida por ellos, con un mismo cooperativista de un mismo barrio [...]. El Estado nos pidió legalidad, nos pidió el título o lo más cerca, para que podamos avanzar en un convenio con las cooperativas. Entonces es así como nos encontramos con esas ocho medias manzanas, que estaban más o menos a regularizarse, que es Malvinas II (Funcionaria municipal del período; 2019, Di Croce Garay).

La misma funcionaria hacía mención a la importancia de la presencia estatal - y a su propia voluntad - en los procesos de regularización dominial: la aprobación de una Ley de expropiación implica su presentación, aprobación en la Legislatura, aprobación del presupuesto, y firma del gobernador. Ese camino puede parecer menos sinuoso cuando el mismo partido político gobierna y tiene mayoría en las Cámaras Legislativas. Sin embargo, si bien esa situación estaba dada (la gobernabilidad y la mayoría en las Cámaras), no fueron elementos suficientes para que la Ley tuviera origen, sino que el primer impulso fue desde el propio barrio. El proyecto de la Ley de expropiación no se dio ante una orden de desalojo, como suele suceder, sino como producto de acciones vecinales organizadas a partir de la demanda de las empresas prestatarias de servicios ante las solicitudes de conexión (que de todos modos terminaron siendo resueltas por las y los habitantes de los barrios).

En el armado del Proyecto y la aprobación de la Ley encontramos, también, situaciones endógenas al barrio que constituyeron elementos relevantes.

En primer lugar, la existencia de la asamblea barrial, a partir de la que se vincularon vecinas y vecinos del barrio, organizaciones sociales
11 G., ex estudiante de arquitectura entrevistada, mencionaba que: "Si bien fuimos a hacer un proyecto, nosotros quedamos encantados de trabajar ahí en el territorio. Entonces nos convocaban a armar lo que habíamos aprendido, que era muy poco, porque la verdad es que hacíamos un montón de cosas, pero de técnica no hacíamos nada. Entonces nos daban la oportunidad, ellos a nosotros, de poner un tirante, de hacer un revoque. Entonces empezamos a construir así con ellos, empezamos a armar una relación, un vínculo, y después terminamos trabajando con hacer actividades para llevar a los chicos al zoológico, con hacer salidas, ¿no? Eso fue para nosotros una cosa magnífica porque desde ahí en más, es como si ese hubiese sido el primer mojón y empezamos a construir lo que vino".

12 Si bien no nos detendremos en ello, creemos interesante destacar la desvinculación entre la formación de grado universitaria y los problemas habitacionales reales, tema planteado por una de las entrevistadas. Los aportes realizados desde distintos grupos de la UNLP, directos o indirectos, lograron complejizar en algún sentido el abordaje de determinadas situaciones del barrio, a pesar de que ello no fuera parte del currículo ordinario de las cursadas. 
y personal del Estado. Por otro lado, en los Fundamentos del proyecto de Ley n. ${ }^{\circ} 13591$ se menciona: "no es ocioso destacar que los propietarios de dichos terrenos, en ningún momento se presentaron en el lugar, por ningún motivo, lo que deja entrever su desinterés por esos inmuebles." Las personas propietarias de la tierra no realizaron denuncia de ocupación ni se hicieron presentes en Malvinas II, generando un antecedente favorable para la aprobación de la Ley. Finalmente, el hecho de que gran parte de la población de Malvinas II pertenezca a la comunidad Q'OM, también fue contemplado como situación favorable para aprobar la expropiación: los fundamentos del proyecto de Ley mencionan recursos legales ${ }^{13}$ que protegen a integrantes de comunidades originarias, al tiempo que da cuenta del proceso de exclusión y expulsión territorial que estas comunidades sufren desde hace siglos.

La aprobación de la Ley fue producto, entonces, de una sumatoria de situaciones, actores y acciones, ninguna de las cuales —en principio- hubieran alcanzado de haber existido aislada.

\section{No todo lo que brilla es oro: la regularización ¿que no fue?}

En las primeras lecturas y entrevistas sobre el barrio Malvinas II, parecía que el proceso había sido en algún sentido "ejemplar" en tanto experiencia de organización barrial coordinada con varias organizaciones sociales y con instituciones estatales. Pero cuando parecía ser el momento culmen de la historia, cuando la expropiación parecía un hecho, todo se frenó. ¿Qué pasó? ¿Qué factores lograron dar por tierra un proceso que estaba a punto de finalizar, y que aparentaba tener al barrio y al Estado coordinando fluidamente? Estas preguntas también encuentran múltiples respuestas que conforman una explicación multicausal.

El primer motivo encontrado fue la mencionada ocupación "del paredón”, aproximadamente durante el año 2008. Unos meses antes de que las y los trabajadores sociales de la SSTUV pudieran ir a verificar las familias que habitaban cada lote, 32 familias ocuparon la superficie comprendida entre las calles 36 a 38, 153 y el paredón que divide lo que iba a ser calle 153 con un predio utilizado para canchas de fútbol. Esta situación generó que ya no pudiera abrirse esa calle, y que la mensura y los planos hechos al momento quedaran obsoletos. Desde la Asamblea y la SSTUV se propusieron posibles soluciones: gestionar desde el Concejo Deliberante una ordenanza municipal que permitiera modificar el recorrido de la calle 153, aprobar un plan urbanístico que contemplara el corrimiento de esa calle, desalojo, realojamiento, etc. Para la Mesa barrial, el responsable de esa ocupación era el propio Estado, y la respuesta era una: o todas las familias, o ninguna.

13 En la presentación del proyecto de Ley se menciona que el mismo "responde a las pautas establecidas en nuestra Constitución Nacional y Provincial, la Ley nacional 23302 sobre política indígena y apoyo a las comunidades aborígenes, la Ley provincial 11331 que adhiere al contenido y alcance de aquella, así como tratados internacionales, entre los que se destaca el Convenio sobre Pueblos Indígenas y Tribales N. ${ }^{\circ} 169$ suscripto ante la Organización Internacional del Trabajo" (Fundamentos de la Ley 13591).
¿Porque vos cómo les decís a esas personas que ocuparon que tienen que salir porque si no, por su culpa, no puedo titular yo? [...]. Hay muchas personas que están ahí porque realmente lo necesitan. De hecho, todos están ahí porque lo necesitan, si no, no estarían (M., vecina entrevistada de Malvinas II; 2019, Di Croce Garay y Jaimarena).

En realidad la consecuencia de que ellos estuvieran asentados ahí es porque el Estado no les dio respuesta para que puedan vivir en otra situación. Por tanto, debíamos responder hacia quienes se habían asentado en las 8 manzanas, más los que estaban en el paredón que era más clandestino aún (G, funcionaria y ex integrante del Mov. Evita; 2019, Di Croce Garay). 
De esta forma, si bien el propio barrio quedaba en algún sentido perjudicado por no poder recibir las escrituras, los vínculos generados en el vecindario durante esos años permitieron no desencadenar una guerra interna entre "la nueva y la vieja ocupación", sino incorporar a las nuevas familias al pedido de regularización.

Además, una serie de cambios en los demás actores del proceso influyeron en que el proceso no tuviera continuidad. Por un lado, cambiaron el personal médico residente de la Salita de Salud, y la coordinación con el nuevo equipo no prosperó. Por otro lado, problemas internos de las organizaciones sociales y políticas influyeron en el funcionamiento de la Mesa Barrial. Durante los años que llevó el proceso (iniciado en el año 2006) empezó a haber diferencias internas entre las organizaciones peronistas que se reflejaron en el funcionamiento de la Mesa barrial. A su vez, en el año 2013 el FPDS sufrió un proceso de fragmentación que llevó a la conformación del Movimiento Patria Grande (partido electoralista). La mayoría de las personas integrantes de la militancia territorial de esa organización eran estudiantes de universidad que, en el proceso de fragmentación, decidieron participar en la conformación del Partido, debilitando el trabajo territorial del Frente. En simultáneo, la organización fue estigmatizada por un diario local de gran influencia, El Día, por una nueva ocupación en las calles 149 entre 34 y 36 . De esta forma, el trabajo realizado para la regularización dominial no solo se vio dificultado por la ocupación del paredón, sino también por los procesos propios de las organizaciones que hasta el momento habían acompañado. Referentes barriales daban cuenta de la importancia que podría haber sugerido el mantenerse unidas y unidos, mediante expresiones como "si hubiésemos seguido con el ritmo de antes, hubiésemos conseguido la regularización dominial" (E., vecino entrevistado; 2019, Di Croce Garay), o "Capaz que, si no me iba, ya íbamos a tener el título" (M. vecina entrevistada; 2019, Di Croce Garay y Jaimarena).

Por último, aparece un factor que también hemos encontrado en relatos de otros barrios: el desgaste producido por lo largo que resultan la mayoría de los procesos que involucran al Estado. El agotamiento, la desazón, la tristeza, la angustia, son sensaciones que registramos en distintos relatos. Las dinámicas familiares y los intereses de la población del barrio también se van modificando, lo que modifica la ecuación barrial. A esta situación, desde el año 2015 se incorpora el contexto de crisis económica que atravesó el país, que lógicamente repercute con mayor dureza en los sectores populares. En contextos donde el trabajo y la alimentación se convirtieron en los principales temas, la regularización dominial quedó desplazada de la lista de necesidades.

En el año 2018, habiendo sucedido en 2015 un cambio de gobierno nacional y provincial, se conformó un nuevo espacio vecinal: la Mesa de Gestión Territorial, integrada por una ex integrante del Movimiento Evita, y los vecinos y vecinas que habían participado o no en la experiencia de la Mesa Barrial del año 2006. Tras relevar la nueva composición familiar del barrio (a través de un plano que colgaron en uno de los comedores barriales, donde cada familia fue anotando su nombre en su terreno), entregaron una presentación a la ex SSTUV solicitando que se retomara el proceso de regularización dominial. La nueva Mesa de Gestión Territorial encabezó el pedido, y tras una serie de reuniones acordaron que el proceso se retomaría, e incorporaría a las familias "del paredón": 
Ahora dijeron "que se queden ahí. Hay una posibilidad: como no hay dónde llevarlos, entonces que se queden como están. Y titularizan ustedes y ellos también. Lo único que no tienen que hacer es tocar el paredón”. Se les habló en asamblea, comunicado, de vecino a vecino. Y los vecinos entendieron eso (M., vecina entrevistada; 2019, Di Croce Garay y Jaimarena).

En esta nueva etapa de la regularización dominial, los repertorios de reclamo estuvieron atravesados por las decisiones de referentes políticos que integran la Mesa, cercanos al kirchnerismo (es decir ex gobernantes, ahora opositores). En sus relatos, indican que se decidió ser "fuerza de choque", e ir a las reuniones "con los dientes apretados a plantear que nosotros íbamos a ir por la regularización de este barrio, y no estábamos dispuestos a ceder" (G., referente entrevistada; 2019, Di Croce Garay). Nuevamente las y los agrimensores y trabajadores sociales de la SSTUV se hicieron presentes en el barrio, no sin antes acordar cuestiones de seguridad con la nueva Mesa de Gestión territorial: durante mayo y junio de 2019 el barrio fue foco de operativos "contra el narcotráfico", que vinieron no solo a profundizar la histórica estigmatización de este barrio, sino también a hacer campaña en pleno año electoral. El clima de hostilidad con el vecindario del barrio generó un evidente efecto boomerang con todo el personal estatal que intentó en esas semanas entrar al barrio, por lo que fue indispensable, una vez más, la coordinación con vecinas de la Mesa Territorial para acceder al diálogo y al barrio.

Según lo indicado por dos entrevistadas, durante el año 2019 se haría entrega de las primeras escrituras del barrio. Si bien no sería para todo el barrio como en un primer momento se pretendió (no pudimos acceder a información sobre cuál es el sector beneficiario, ni las causas de su elección), sería un primer paso luego de tantos años de espera. Trece años después de iniciado el proceso de regularización dominial de un barrio de 17 años de antigüedad, pareciera posible empezar a acceder a la titulación de las tierras. Pero todo "en potencial", entre signos de preguntas. ${ }^{14}$

\section{Aportes de las acciones colectivas}

Haber recorrido la historia de la ocupación, urbanización y regularización dominial del barrio Malvinas II, nos acercó a reconocer una serie de aportes que la acción colectiva brindó en cada una de esas instancias. Así como propone Tilly (1978), en estas acciones encontramos intereses en común, organización del colectivo, movilización y contexto político-social-cultural-económico influyente. En este apartado indagaremos en las características que tomaron las intervenciones desarrolladas desde la organización vecinal (incluyendo aquí los espacios organizativos propios del barrio, como el de la comunidad toba), las organizaciones sociales, el aporte técnico-profesional, y las instituciones estatales.

\section{Aportes desde "lo comunitario": la organización vecinal}

14 El trabajo de campo fue realizado durante el año 2019, y no accedimos a información que verifique si finalmente se pudo concluir o no la regularización dominial.
La necesidad es la que te mueve. Si vos no lo necesitás no vas a salir. Y el Estado, que tendría que estar acá, está esperando a que vayas (M., vecina entrevistada: 2019, Di Croce Garay y Jaimarena). 
En primer lugar, encontramos acciones vecinales que dieron carácter colectivo a la construcción del barrio.

Por un lado, así como fue mencionado, la población de Malvinas II se compone por personas integrantes de distintas comunidades (toba y paraguaya), cada una de las cuales trajo sus propias tradiciones en prácticas comunitarias. En el caso de la comunidad paraguaya, la fuerte relación con el mundo laboral vinculado a la construcción puede registrarse en la consolidación de algunas de las viviendas del barrio. Asimismo, la comunidad toba traía una tradición de organización vecinal vinculada a valores de ayuda familiar y organización comunitaria que fueron retomadas en los espacios de asamblea y en las estructuras a partir de las que se organizaron:

En uno de los encuentros que tuvimos con otras organizaciones nos cuentan que a ellos les iba muy bien, para no generar desgaste en estos procesos que son largos, con elegir un delegado por manzana. Este delegado por manzana iba a tener la voz para formar parte de estas asambleas. En estas asambleas intentábamos generarlas una por semana, cada quince días, y ese delegado podía trasladar a sus vecinos y familias a quienes representaba. Generamos esa modalidad: delegado por manzana que tenía la responsabilidad de llevar y traer la voz de lo discutido y propuesto (G., integrante del Movimiento Evita y ex Subsecretaria Municipal de Inclusión Social; 2019, Di Croce Garay).

En algunos de los problemas de escala barrial encontramos respuestas colectivas. Entre ellos, la posibilidad de "re-tomas" fueron un conflicto principalmente en los primeros años del barrio. Este concepto lo encontramos en las entrevistas para hacer mención a los intentos de que se ocupen los loteos o viviendas ya ocupadas:

Hubo muchas usurpaciones de casitas al principio. Vos salías, te ibas a visitar a un familiar o quien sea, y a la semana volvías y estaban usurpando tu terreno, y te decían "si vos no sos la dueña del terreno". Entonces cuando ibas a hacer el reclamo decías "Usurparon una casita allá", "Y señora, pero nadie es dueño, tampoco es tuyo". (M., vecina de Malvinas II; 2019, Di Croce Garay y Jaimarena).

Ante estos episodios, se desarrollaron redes de cuidado de viviendas en el vecindario, donde cada habitante cuidaba de su propia casa y de las casas vecinas.

En lo que refiere a la regularización dominial, el paso inicial fue dado desde la asamblea barrial, coordinada con organizaciones sociales, organizadas mediante los cuerpos de personas delegadas por manzana, encargadas de acercar propuestas y difundir decisiones. Iniciados los trámites de regularización dominial, la existencia de cuerpos delegados permitió, además del desarrollo de procesos democráticos de decisiones colectivas, garantizar la difusión de información entre las familias. La expropiación requirió tareas de mensura del barrio realizadas desde el Estado, para las cuales la Mesa Barrial se ofreció a colaborar con el trabajo, argumentando que son sus componentes quienes conocen el barrio y las familias. Así, el trabajo se desarrolló en conjunto entre vecindario y Estado.

Una de las excusas para no conectar el servicio de electricidad era que no existía un plano oficial que permitiera conocer el barrio y planificar las tareas. La referente barrial entrevistada mencionaba que, 
como respuesta a la empresaria prestadora del servicio, llevaron un día el plano realizado por los maestros y maaestras mayores de obra del barrio:

“AAcá tenés! ¡te lo dibujé!, jte lo dibujamos!”, le dije. “Mi papá hizo todo un planito así con otros vecinos. ¿Ahí conocé el lugar? ¿Eh? Y dijeron "bueno, mañana no porque tenemos que organizarnos, el jueves vamos a hacer un paneo de todo, vamos a ir a verificar el lugar, el espacio y a conocer, ¿vos me podés dar ese planito?" "Si, tomá fotocopia, ahí tenés, andá y fijate“ (M., vecina entrevistada; 2019, Di Croce Garay y Jaimarena).

Este mismo plano fue también insumo como croquis en los relevamientos realizados por la SSTUV.

\section{Aportes desde las Organizaciones sociales}

En Malvinas II se evidencia un proceso de organización progresivo, vinculado en un primer momento a reuniones familiares $\mathrm{y} / \mathrm{o}$ vecinales, que luego configuraron redes más amplias, como la Mesa Barrial, a partir de la intervención de organizaciones sociales. Si bien la propuesta original de comenzar un proceso de ocupación de tierras y/o regularización dominial parte del vecindario, los abordajes tuvieron particularidades propias derivadas, en parte, de las estructuras organizativas de las organizaciones intervinientes.

El primer aporte reconocido por los y las vecinas entrevistadas son las pautas sobre la estructura de delegadxs y funcionamiento de las asambleas, que se combinó con los sistemas organizativos propios de les habitantes del barrio. La Mesa Barrial de Malvinas II, por su parte, fue el resultado de una sumatoria de organizaciones y espacios barriales que no necesariamente contaban con áreas de Hábitat, pero que sí contaban con "contactos" con funcionarias y funcionarios políticos e integrantes de la UNLP.

Durante las negociaciones, las organizaciones sociales acercaron la posibilidad de difusión en medios alternativos (principalmente radios comunitarias), el contacto con colectivos de profesionales técnicos y con personal funcionario público. Los mismos vecinas y vecinos del barrio indican, sin embargo, que para ellos fue muy importante que las personas militantes estén presentes en las negociaciones porque "hablan mejor".

Más allá del reconocimiento que merecen todas las escalas organizativas, no podemos negar que los contextos políticos y las trayectorias de cada una de las organizaciones fueron condicionantes que generaron aportes particulares: el doble rol jugado por aquellos integrantes del Movimiento Evita que eran al mismo tiempo funcionarios públicos, permitió el avance de la presentación de la Ley de expropiación.

\section{Aportes de estudiantado universitario y profesionales. El aporte técnico}

A lo largo del proceso de ocupación y urbanización del barrio Malvinas II registramos intervenciones realizadas por profesionales y estudiantes de la UNLP que, así como fue mencionado, fueron elementos relevantes para la aprobación de la Ley de expropiación. A través de colectivos profesionales, proyectos de extensión universitaria, trabajos prácticos, encontramos el aporte de herramientas como análisis de 
agua, proyectos de arquitectura, asesoramiento legal. Estas intervenciones, con las que no contaba ni las organizaciones sociales ni el vecindario de cada barrio y que tampoco fueron brindadas desde instituciones estatales, contribuyeron de forma directa en el armado de la Ley de expropiación, así como en la gestación y fortalecimiento de vínculos entre los y las habitantes del barrio.

\section{Vínculos con personal estatal y funcionariado público}

Cuando en este trabajo nos propusimos indagar en los vínculos entre los barrios y el Estado, buscábamos repertorios o mecanismos a través de los cuales los barrios logran ser atendidos. En esa búsqueda, no encontramos prácticas innovadoras: los cortes de calles fueron la práctica más utilizada, a partir de la cual se obtuvieron en algunos casos reuniones con personal funcionario público. Esas reuniones fueron de gran importancia en las instancias de negociación por la regularización dominial. Sin embargo, reconocemos que en la vinculación con el personal funcionario también fueron relevantes los contactos facilitados desde las organizaciones sociales. Ambos elementos, los repertorios de reclamo y los contactos a través de organizaciones sociales, resultaron necesarios para iniciar y avanzar los procesos de regularización dominial. Al respecto, una vecina entrevistada, ante la pregunta sobre cómo fue que se logró conseguir la Ley mencionaba instituciones estatales como el Concejo Deliberante, "charlas, debates, personas que acompañaron continuamente". Si bien ella misma valoraba la Mesa Barrial y la organización de las vecinas y vecinos, daba un gran valor a "los y las compañeras que te ayudan desde adentro" (refiriéndose a integrantes de organizaciones sociales que son parte del personal estatal) (M., vecina entrevistada; 2019, Di Croce Garay y Jaimarena). En el mismo barrio, sin embargo, desde la nueva Mesa de Gestión Territorial (aquella conformada en el año 2018 que fue descrita en el apartado "No todo lo que brilla... "), nos indicaron que la clave es la participación barrial:

Nos hemos juntado en el territorio, nos hemos juntado los vecinos, las organizaciones, por distintos temas. En función de eso, en una Mesa de gestión territorial [...] hemos pactado resolver los conflictos que tenemos en este caso en Malvinas. En función de esa Mesa nos hemos sentado con ese Estado, y este Estado nos ha escuchado y ha empezado a resolver estas demandas que nosotros teníamos. Dentro de todas esas demandas, uno de los puntos fue la regularización dominial. Por eso digo que es la organización la que nos ha dado la oportunidad nuevamente de empezar a resolver nuestros conflictos territoriales (G., Integrante de la Mesa Territorial; 2019, Di Croce Garay).

\section{Reflexiones}

En relación a la indagación realizada, nos surgen una serie de reflexiones que buscan exponer aspectos valorativos del estudio, así como aportar a repensar prácticas cotidianas de la acción colectiva barrial y de las organizaciones sociales.

En primer lugar, podemos decir que, en la ocupación de la tierra, su urbanización y su regularización dominial, la acción colectiva de la población del barrio acompañada de organizaciones sociales fue un aspecto clave. En esos procesos organizativos confluyen las estrategias y 
dispositivos construidos por sus propias y propios habitantes, con aquellos movilizados desde organizaciones barriales, sociales y técnicas.

Sin embargo, si bien no era parte central de la búsqueda, nos encontramos revisando la acción estatal. Encontramos en ellas acciones propias de su dimensión abstracta (donde se articulan relaciones sociales), y acciones pertenecientes a una dimensión material (trazadas en su cotidiano por intereses, rutinas, burocracias). Como protagonistas de esas acciones, encontramos en esas agencias estatales que, muchas veces, quienes allí trabajan como profesionales son a su vez militantes, quienes circulan en ámbitos cuyos límites y alcances son difíciles de delimitar. Este doble rol que encontramos, esa porosidad propia de muchos actores estatales, se suele expresar en el territorio.

Por último, resulta relevante el análisis de procesos espaciales a partir de su entrecruzamiento con las temporalidades diversas que los atraviesan, donde los contextos sociales, económicos y políticos varían y van redefiniendo las urgencias y prioridades tanto de habitantes de barrios como de organizaciones barriales, sociales y técnicas. En esa perspectiva, reconocer el carácter crónico de estos procesos puede aportar a la construcción de objetivos a largo plazo en la territorialización y estrategias de construcción de poder de las organizaciones. 


\section{Referencias bibliográficas}

Bonafina, Javier (2014). Una sociedad en la bruma de la ciudad fantasma: La Plata 1880-1914 (Tesis de Maestría). Universidad Torcuato Di Tella, Ciudad de Buenos Aires, Argentina.

Del Río, Juan Pablo y González, Pablo (2018). Los asentamientos populares informales en el Gran La Plata Una geografía cambiante con más de tres décadas de persistencia. En Cravino, María Cristina (Ed.). La ciudad (re)negada Aproximaciones al estudio de asentamientos populares en nueve ciudades argentinas (pp. 161-194). Los Polvorines: Ediciones UNGS.

Di Virgilio, María Mercedes y Rodríguez, María Carla (Eds.) (2014). Producción social del hábitat: abordajes conceptuales, prácticas de investigación y experiencias en las principales ciudades del Cono Sur. Ciudad Autónoma de Buenos Aires: Editorial Café de las Ciudades.

González, Manuela y Silber, Julia (2003). La universidad en el barrio. "Abordaje interdisciplinario para la promoción de los derechos de la niñez y la adolescencia en el barrio Malvinas de la ciudad de La Plata". Proyecto de Extensión Universitaria-UNLP, 2003.

Herzer, Hilda y Pírez, Pedro (1993). Gestión urbana en ciudades intermedias de América Latina. Nairobi: UNCHS.

Herzer, Hilda, Di Virgilio, Mercedes, Redondo, Adriana y Rodríguez, María Carla (2006). ¿Informalidad o informalidades? Hábitat popular e informalidades urbanas en áreas urbanas consolidadas (Ciudad de Buenos Aires). En Seminario Latinoamericano Teoría y Política sobre Asentamientos Informales. Seminario llevado a cabo en la UNGS, Los Polvorines, Buenos Aires. Recuperado el 10 de junio de 2021 de: https://dialnet.unirioja.es/descarga/articulo/2756182.pdf.

Piovani, Juan Ignacio (2007). La entrevista en profundidad. En Marradi, Alberto, Archenti, Nélida y Piovani, Juan Ignacio (Eds.), Metodología de las ciencias sociales (pp. 215-225). Buenos Aires: Emecé Editores.

Pírez, Pedro (2016). Las heterogeneidades en la producción de la urbanización y los servicios urbanos en América Latina. Territorios, 34, 87-112. DOI: dx.doi.org/10.12804/territ34.2016.04.

Relli, Mariana (2008). Reflexiones en torno al trabajo con organizaciones comunitarias para la implementación de programas habitacionales, a partir del es- tudio del barrio Las Malvinas de La Plata, provincia de Buenos Aires. Huellas, 12, 198-224. Recuperado el 16 de junio de: http:/ / www.biblioteca.unlpam. edu.ar/pubpdf/huellas/n12a11relli.pdf.

Svampa, Maristella (2009). Protesta, movimientos sociales y dimensiones de la acción colectiva en América Latina. En Conferencia para las Jornadas de Homenaje a C. Tilly. Fundación Carolina, Universidad Complutense de Madrid, España.

Tamagno, Liliana (2001). Nam qom hueta'a na doqshi lma'. Los tobas en la casa del hombre blanco. Identidad, memoria y utopía. La Plata: Ediciones Al Margen.

Tilly, Charles (1978), From Mobilization to Revolution, New York: McGraw-Hill Publishing Company.

Vallejo, Gustavo (2015). Proyecto urbano y sectores populares en la génesis de La Plata. Rosario: Prohistoria.

Vila, Mariana (2011). En los zapatos de otros: La construcción de subjetividad colectiva en un movimiento de trabadores desocupados (Tesis de grado). Facultad de $\mathrm{Hu}-$ manidades y Ciencias de la Educación, Universidad Nacional de La Plata, La Plata.

Villar, Lidia (2007). La organización territorial del movimiento de trabajadores desocupados Aníbal Verón del barrio Malvinas de la ciudad de La Plata (Tesis de grado). Facultad de Humanidades y Ciencias de la Educación, Universidad Nacional de La Plata, La Plata.

Zibechi, Raúl (2008). Territorios en resistencia. Cartografía politica de las periferias urbanas latinoamericanas. Buenos Aires: Ediciones Lavaca.

Zibecchi, Carla (2019). ¿Interlocutoras del Estado? El caso de las destinatarias de programas sociales y las referentes de organizaciones territoriales en la Argentina. Prospectiva. Revista de Trabajo Social e intervención social, 27, 31-54. DOI: https://doi. org/10.25100/prts.v0i27.7269.

\section{Fuentes}

RPPVAP: Registro Público Provincial de Villas y Asentamientos Precarios (Ley 14.449). Subsecretaría Social de Tierras Urbanismo y Vivienda. Ministerio de Infraestructura y Servicios Públicos de la Provincia de Buenos Aires. Actualizado el 31/12/2015

RENABAP: Registro Nacional de Barrios Populares. 
Di Croce Garay, Andrea (2021). Ocupar, urbanizar, regularizar desde la acción colectiva: indagaciones sobre el barrio Malvinas II de La Plata. Hábitat y Sociedad, 14, 33-50.

<https://doi.org/10.12795/HabitatySociedad.2021.i14.03>

$\bigcirc$ 